\title{
Semiquantitative Risk Assessment Method for Groundwater Source Protection Using a Process-based Interdisciplinary Approach
}

\author{
Robert Duda $^{1}$ (D) $\cdot$ Robert Zdechlik $^{1}$ (D) . Jarosław Kania ${ }^{1}$ (D)
}

Received: 12 April 2021 / Accepted: 28 June 2021 / Published online: 20 July 2021

(C) The Author(s) 2021

\begin{abstract}
Potable groundwater resources are at risk as a result of industrial development and an increase in fertilizer use. Protection of the groundwater supply may require the establishment of groundwater source protection zones (GSPZs) to allow the implementation of protective measures. The aim of this study was to develop a new approach to groundwater source risk assessment (GSRA). The risk was defined as the highest of the risks identified for individual potential sources of contamination (PSCs). The risk resulting from a given PSC is the combination of its adverse impact on groundwater, unwanted event probability, and adverse effect and annoyance to the population. A multicriteria assessment method was designed to estimate indices of the potential groundwater impact of industrial facilities and noninert waste landfills with the range and weight method. Application of the proposed approach was tested considering an idealized model and three scenarios involving various industrial PSCs and fertilization practices. The overall nitrogen load was compared to the maximum effective nitrogen load for the crops in question. Sensitivity analysis of this methodology revealed that the main factors influencing the risk to the water supply include the nonreactive contaminant mass load in PSC leachate and the ratio of the groundwater volume abstracted from wells to the amount of water flowing from PSCs into wells, which determines the dilution degree of the contaminant mass. This proposed interdisciplinary approach to GSRA provides a robust basis to reach decisions on GSPZ establishment and the development of a groundwater risk analysis methodology.
\end{abstract}

Keywords Water supply · Risk analysis · Contaminant source · Groundwater pollution · Land use $\cdot$ Nitrate
Abbreviations
GSPZ Groundwater source protection zone
GSRA Groundwater source risk assessment
PSC Potential source of contamination
PRA Probabilistic risk analysis

Robert Duda

duda@agh.edu.pl

1 Faculty of Geology, Geophysics and Environmental Protection, AGH University of Science and Technology, Mickiewicza 30, 30-059 Kraków, Poland 
WHPA Wellhead protection area

$R \quad$ Risk to the groundwater source

$L U \quad$ Adverse impact of the PSC on the groundwater quality

$P A \quad$ Probability of occurrence of the unwanted event

$A E \quad$ Adverse effect of aquifer contamination

$A_{A E} \quad$ Annoyance caused by the adverse effect to water users

\section{Introduction}

Groundwater contamination risk analysis is a basic part of the assessment process regarding the necessity of implementing potential protective measures on a regional scale, mainly in regard to catchment areas. However, a particularly important type of analysis of the groundwater contamination risk combined with the human health risk encompasses water source evaluation. This analysis is performed to assess the need for groundwater source protection zone (GSPZ) establishment and pollution prevention measures. The World Health Organization has recommended that a drinking water safety plan and risk management system should be developed to manage groundwater resources (WHO 2017a). This is necessary to prevent possible hazards within wellhead protection areas (WHPAs).

Groundwater source risk assessment (GSRA) is performed based on analysis of the impact of land use (Huan et al. 2018; Li et al. 2018). Land use forms potentially threatening the quality of abstracted groundwater mainly include agricultural and point sources of contamination (Lima et al. 2019; Li et al. 2020). In regard to the agricultural impact, risk analysis has been conducted targeting nitrate pollution (Su et al. 2013; Teng et al. 2019; Zambito Marsala et al. 2020). In addition to qualitative methods for groundwater risk estimation ( $\mathrm{Li}$ et al. 2015; Zhang et al. 2016; Duda et al. 2020), advanced methods such as numerical modeling of mass transport through the vadose zone and saturated aquifer have been adopted (Troldborg et al. 2009; Enzenhoefer et al. 2012; Huan et al. 2015, 2020; Locatelli et al. 2018). Enzenhoefer et al. (2015) presented a more holistic and probabilistic approach, which additionally considered, inter alia, aggregation of the impacts stemming from different contaminants and spill locations into a cumulative impact on the risk and a method considering the stochastic nature of spill event accounting when converting the aggregated impact into risk estimates. Furthermore, Rodak and Silliman (2012) proposed an advanced approach combining probabilistic risk analysis (PRA) with fault trees of contamination sources, in addition to chemical transport modeling and human health impact assessment to estimate the health effects on abstracted water users. The methods adopted in PRA of engineering system failure scenarios have been described by Ostrom and Wilhelmsen (2019) and Modarres and Kim (2020). Fuzzy fault tree analysis in risk assessment of water resource development plans was performed according to Abedzadeh et al. (2020).

Moreover, it remains a problem that most GSRA approaches usually adopt a specific concentration of the groundwater contaminant under analysis as an assessment basis (for example, nitrates), i.e., a situation that has already occurred as a result of the actual impact of pollution sources. However, these sources are usually not specified and characterized in detail. In the case of industrial facilities, overall facility characterization is lacking, which should consider not only technical aspects but also nontechnical aspects that may influence the failure probability. The approaches adopted to date typically still do not involve simultaneous estimation of the event probability and chemical compound mass emitted from a potential source of contamination (PSC). 
The deficiencies identified in existing GSRA methods particularly concern the estimation of the potential total effective nitrogen load for a given crop. This total nitrogen mass is dissolved in water, and as nitrates, it moves toward the aquifer and only then is it transported to the water source. Thus, when analyzing the risk of nitrates reaching a given well at concentrations that threaten the health of users, it is important to estimate the risk directly originating from PSCs, not solely the risk, which is the observed effect of the PSC impact. Furthermore, existing GSRA approaches do not consider the annoyance attributed to the adverse effect of the PSC impact to water users.

The purpose of this article is to propose a method to bridge the indicated gaps by establishing a comprehensive and interdisciplinary approach to GSRA. Improving the GSRA quality is particularly important within the context of groundwater protection given its increasing scarcity. The proposed method accounts for both those risk factors that have been previously considered by other researchers and additional factors considered for the first time in this study. Our source-pathway-receptor approach is a semiquantitative and modular framework for a process-based GSRA.

\section{Methodology}

\subsection{Calculation of the Degree of Risk}

The method and presented example concern a situation where a well field contains a delineated GSPZ, and a risk analysis is required to determine the necessity of its legal establishment so that a groundwater protection plan can be implemented. The purpose of implementing this plan is to eliminate the possibility of degradation in the quality of abstracted groundwater resulting in discontinuation of the water supply originating from this source to users. The GSRA method adopted assumes that at the time of assessment, the well field draws uncontaminated water, and no PSCs located within the GSPZ have released any contamination yet.

In the approach adopted, the greatest of the risks identified for the individual PSCs located within the GSPZ is regarded as the risk of groundwater source contamination:

$$
R=\max R_{i}
$$

where:

$$
R_{i}=L U_{i} \cdot P A_{i} \cdot A E_{i} \cdot A_{A E i}
$$

where $R$ is the degree of risk to the groundwater source, $R_{i}$ is the risk caused by a given PSC, $i$ is the number of PSCs, $L U_{i}$ is the adverse impact of the PSC on the groundwater quality, $P A_{i}$ is the probability of occurrence of the unwanted event/failure, $A E_{i}$ is the adverse effect of aquifer contamination and $A_{A E i}$ is the annoyance caused by the adverse effect to water users.

In our approach, the factors determining the risk to groundwater sources include the adverse effect of any unwanted events and the annoyance due to this effect. If no such effect occurs $(A E=0)$ or no annoyance ensues $\left(A_{A E}=0\right)$, then there is no risk to the groundwater source $(R=0)$. Where a certain PSC yields an adverse effect, the increase in risk is affected by (i) the increase in severity of its impact, (ii) the increase in contaminant emission potential, and (iii) the increase in annoyance. 
The performed GSRA results in appropriate decisions concerning water source management. If risk occurs $(R>0)$, GSPZ establishment should be required to protect the water resources occurring within this zone.

An organigram of the factors considered in GSRA and a process flowchart are shown in Figs. 1 and 2, respectively.

\subsection{Adverse Impact (LU)}

The degree of the adverse impact of PSCs on groundwater is determined using relevant classifications (Table 1). The adverse impact of a given PSC is assumed to depend on:



Fig. 1 Organigram of the factors considered in GSRA 




Fig. 2 Flowchart of the GSRA process

- the chemical compound mass that may be emitted by a given source,

- the concentration of chemical compounds in the leachate,

- the toxicity of the chemicals that may be emitted, 


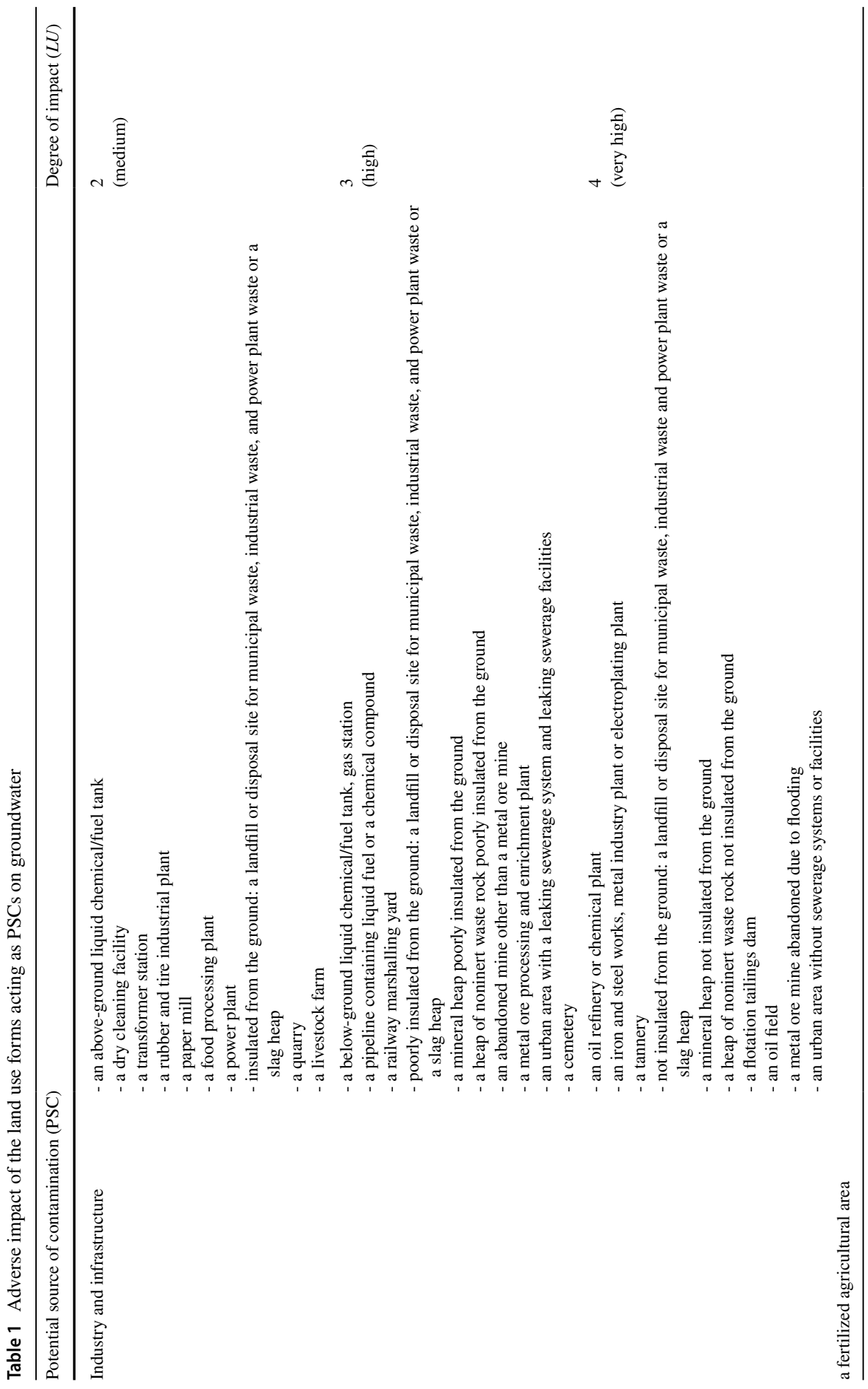


- the depth of the groundwater table, and

- the degree of insulation of the PSC from the ground.

\subsection{Probability of an Unwanted Event}

An unwanted event entails the worst-case emission of a contaminant into groundwater among the emissions possible for a given PSC. The probability of an unwanted event (PA) is defined in a different manner depending on the type of land use.

\subsubsection{Industrial and Infrastructure Facilities and Installations}

The $P A$ is determined by assessing the technical conditions of the facility in question. The technical conditions are determined based on the age of the facility, the method of its construction, the scope and frequency of periodic checks/inspections, and the fail-safe protection measures employed. Depending on the scenario implemented, risk analysis may concern the current or projected technical conditions.

The $P A$ is expressed on a scale from 0 to 1 (Table 2), where a value of 0 corresponds to the impossibility of an accident/failure occurring within a 25-year horizon under any scenario considered. A value of 1 corresponds to a situation where a failure/accident will occur at a $100 \%$ probability within a 25 -year horizon under at least one scenario. A span of 25 years is considered because this period is adopted as a limit when delineating the GSPZ range based on the isochrone of the arrival of nonreactive contaminants stemming from the land surface at the well.

To determine the $P A$ for industrial and infrastructure-type PSCs, a two-stage approach is adopted (Fig. 2). Stage I consists of a qualitative assessment: if for the PSC in question, the probability of event occurrence is low $(P A \leq 0.3)$, in subsequent stages, it is then assumed that there is no adverse effect $(A E=0)$ and consequently no risk to the well field $(R=0)$. If the assessment result indicates that $0.3<P A \leq 0.5$, the degree of the adverse effect of the event is then determined. In contrast, if qualitative assessment demonstrates that the probability of occurrence of an unwanted event is very high $(P A>0.5)$, stage II of $P A$ determination thus follows (quantitative assessment).

Step I - qualitative $P A$ assessment

It is assumed that the $P A$ of an industrial and infrastructure facility results in possible groundwater contamination increase with deteriorating technical conditions of the facility in question. The technical conditions of an industrial or infrastructure facility are determined by the construction manner of the facility and its anti-accident protection

Table 2 Classification of the PA for infrastructure and industrial facilities and installations
Probability of an unwanted event

\begin{tabular}{ll}
\hline $0 \leq P A \leq 0.3$ & low \\
$0.3<P A \leq 0.5$ & high \\
$0.5<P A \leq 0.7$ & very high \\
$0.7<P A \leq 1.0$ & extremely high
\end{tabular}


measures $(C)$, its operation or production technology $(T)$ and the frequency and scope of inspections and fail-safe protection measures and procedures to be followed in the event of an incident $(I M)$. Nontechnical factors are also considered in the assessment (Table 3), namely, the possibility of natural $(N)$ and economic and legal $(E L)$ random events and human errors $(H)$. Natural events include geohazards, which are extreme weather events, landslides caused by natural factors, earthquakes, and tsunamis. Economic and legal factors include the liquidation of a company as a result of bankruptcy, a change in business profile, or a certain negligence and omission resulting from cost cutting.

Human errors include the deliberate flouting of approved procedures and norms, negligence, lack of responsibility, lack of necessary qualifications and competences among hired employees without compliance with relevant requirements, bending to pressure stemming from superiors for fear of losing employment, and pressure on subordinates to

Table 3 Assessment criteria and ranks of factors influencing the risk of groundwater contamination

\begin{tabular}{|c|c|}
\hline Criterion, factor & Rank \\
\hline Construction manner & $C_{r}$ \\
\hline $\begin{array}{l}\text { - very careful, with only proper materials used and best available technics (BAT) applied } \\
\text { throughout }\end{array}$ & 0.1 \\
\hline - careful, with inappropriate materials/technology applied at certain locations & 0.4 \\
\hline - mostly careless, with inappropriate materials used frequently & 0.7 \\
\hline - careless, with inappropriate materials used & 1.0 \\
\hline Technical inspections and maintenance of the facility and its safeguards & $I M_{r}$ \\
\hline $\begin{array}{l}\text { - very careful, with only proper materials/equipment used and BAT applied throughout; } \\
\text { very frequent }\end{array}$ & 0.1 \\
\hline - usually careful, with inappropriate materials/equipment used in certain areas; frequent & 0.4 \\
\hline - usually careless, with inappropriate materials/equipment used frequently; infrequent & 0.7 \\
\hline - fragmented, sporadic & 1.0 \\
\hline Operating or production technology & $T_{r}$ \\
\hline $\begin{array}{l}\text { - very modern with BAT applied, including a very small amount of liquids containing } \\
\text { chemicals in circulation and solid waste }\end{array}$ & 0.1 \\
\hline - modern, with a small amount of liquids containing chemicals in circulation and waste & 0.4 \\
\hline - modern, with a large amount of liquids containing chemicals in circulation and waste & 0.7 \\
\hline - obsolete, with a very large amount of liquids containing chemicals in circulation and waste & 1.0 \\
\hline Natural random event/economic or legal random event/human errors & $N_{r} / E L_{r} / H_{r}$ \\
\hline - very unlikely & 0.1 \\
\hline • unlikely & 0.4 \\
\hline - likely & 0.7 \\
\hline - very likely & 1.0 \\
\hline$\overline{I_{\text {in }}}$ & $P A$ \\
\hline$\bullet<5$ & 0.2 \\
\hline - 5-10 & 0.4 \\
\hline • $10-15$ & 0.6 \\
\hline$\bullet>15$ & 0.8 \\
\hline
\end{tabular}


force them to act improperly or to refrain from implementing certain actions, reporting irregularities, achieving group solidarity, etc.

It is assumed that the degree of impact of individual factors determining the technical conditions of industrial and infrastructure facilities varies, which is expressed by their weights. The weights adopted for the individual factors are $5\left(C_{w}\right.$ and $\left.I M_{w}\right), 4\left(T_{w}\right), 3\left(N_{w}\right), 2\left(E L_{w}\right)$ and $1\left(H_{w}\right)$. Each factor can attain a value (rank) ranging from 0.1 to 1 (Table 3 ). We define the index of the potential impact of industrial and infrastructure sources on groundwater as:

$$
I_{\text {in }}=C_{r} \cdot C_{w}+I M_{r} \cdot I M_{w}+T_{r} \cdot T_{w}+N_{r} \cdot N_{w}+E L_{r} \cdot E L_{w}+H_{r} \cdot H_{w}
$$

Depending on the value of the $I_{\text {in }}$ index, the $P A$ is estimated for industrial and infrastructure facilities (Table 3).

Regarding noninert waste landfills, following the concept proposed by Zhang et al. (2016), several factors are considered that impact the risk of groundwater contamination. It is assumed that factors related to the landfill design and nature of the waste stored provide a more reliable estimate of the risk of groundwater contamination. The factors ultimately considered for assessment purposes include the type of waste $(T)$, the method of landfill insulation from the ground (I), the method of waste covering ( $\mathrm{Cov}$ ) and the degree of compaction ( $\mathrm{Cmp}$ ).

The degree of impact of the individual factors varies, which is expressed by their weights. Weights of $5\left(I_{w}\right.$ and $\left.C o v_{w}\right)$ or $3\left(T_{w}\right.$ and $\left.C m p_{w}\right)$ were assumed for the individual factors. Each factor can attain a value (rank) ranging from 0.1 to 1 (Table 5). The potential impact of a noninert waste landfill on groundwater is determined by the $I_{l}$ index:

$$
I_{I}=T_{r} \cdot T_{w}+I_{r} \cdot I_{w}+\operatorname{Cov}_{r} \cdot \operatorname{Cov}_{w}+\operatorname{Cmp}_{r} \cdot \operatorname{Cmp}_{w}
$$

Depending on the calculated $I_{l}$ index value, the probability of an unwanted event $(P A)$ considering a landfill and a noninert waste heap is accordingly estimated (Table 4).

Step II - quantitative $P A$ calculation

In regard to industrial and infrastructure PSCs, an unwanted event involves the worst-case emission of a certain contaminant into groundwater among the emissions possible for a given PSC. The probability is quantitatively estimated as:

$$
P A=P A_{B Z} \cdot P S F
$$

where $P A_{B Z}$ is the probability of failure occurrence for a given PSC (Eq. 6), and PSF is the combined probability of security failure, i.e., the failure of individual independent fail-safe protections (Eq. 7).

$$
P A_{B Z}=\max \left(P a_{i} \cdot \max P c_{j}\right)
$$

where $P a_{i}$ is the probability of occurrence of the accident initiating the emission of a certain contaminant from a given PSC into the environment, $i$ is the number of initiating accidents in question, $P c_{j}$ is the probability of occurrence of a certain condition triggering a given accident initiating contaminant emission $\left(P a_{i}\right)$, and $j$ is the number of situations conditioning a given initiating accident.

$$
P S F=\max P S F_{i}
$$

where $P S F_{i}$ is the probability of failure of the fail-safe protection measure in question, and $i$ is the number of protection measures. Examples of protection measures include process 
Table 4 Criteria to assess and rank the factors impacting the risk of groundwater contamination as a result of the potential impact of a landfill and the relationship between $P A$ and $I_{l}$

\begin{tabular}{|c|c|}
\hline Criterion, factor & Rank \\
\hline Waste type & $T_{r}$ \\
\hline - municipal & 0.5 \\
\hline - hazardous/toxic & 1.0 \\
\hline Manner of insulation from the ground & $I_{r}$ \\
\hline $\begin{array}{l}\text { - double insulation: alternately } 2 \text { combined layers - synthetic material (PVC or HDPE) and } \\
\text { compacted clay (thickness } \geq 1 \mathrm{~m}, k^{*} \leq 1 \cdot 10^{-9} \mathrm{~m} / \mathrm{s} \text { ), and drainage }\end{array}$ & 0.1 \\
\hline $\begin{array}{l}\text { - synthetic material (PVC or HDPE) and compacted clay (thickness } \geq 1 \mathrm{~m}, k \leq 1 \cdot 10^{-9} \mathrm{~m} / \mathrm{s} \text { ), and } \\
\text { drainage }\end{array}$ & 0.4 \\
\hline - compacted clay (thickness $\geq 1 \mathrm{~m}, k \leq 1 \cdot 10^{-9} \mathrm{~m} / \mathrm{s}$ ) and drainage & 0.7 \\
\hline - no insulation & 1.0 \\
\hline Waste covering & $\operatorname{Cov}_{r}$ \\
\hline $\begin{array}{l}\text { - synthetic material (PVC or HDPE), compacted clay (thickness } \geq 0.5 \mathrm{~m}, k>1 \cdot 10^{-9} \mathrm{~m} / \mathrm{s} \text { ), soil } \\
\text { and drainage }\end{array}$ & 0.1 \\
\hline - clay (thickness $\geq 0.5 \mathrm{~m}, k>1 \cdot 10^{-9} \mathrm{~m} / \mathrm{s}$ ), soil and drainage & 0.4 \\
\hline - loam (thickness $\geq 0.5 \mathrm{~m}, k>1 \cdot 10^{-7} \mathrm{~m} / \mathrm{s}$ ), soil and drainage & 0.7 \\
\hline - soil only or no cover & 1.0 \\
\hline Waste compaction & $\mathrm{Cmp}_{r}$ \\
\hline - compacted, multiple compactor passes or permanent waste solidification & 0.5 \\
\hline - poorly compacted, a few compactor passes or partial waste solidification & 0.8 \\
\hline - noncompacted or nonsolidified & 1.0 \\
\hline$\overline{I_{l}}$ & $P A$ \\
\hline$\bullet<5$ & 0.2 \\
\hline • 5-10 & 0.4 \\
\hline - $10-15$ & 0.6 \\
\hline$\bullet>15$ & 1.0 \\
\hline
\end{tabular}

$k$ is the hydraulic conductivity

automation, safety automation, operator or system action, isolation or protection systems, fail-safe protection procedures, etc.

\subsubsection{Fertilized Agricultural Areas}

The probability of nitrate emissions into groundwater originating from diffuse pollution sources (fertilized areas) was calculated in an approximate manner. Atmospheric nitrogen

Table 5 Classification of the unwanted event probability in fertilized areas

\begin{tabular}{lll}
\hline$F_{N}$ & PA & \\
\cline { 2 - 3 }$\left[\mathrm{kg} \cdot \mathrm{ha}^{-1} \cdot \mathrm{y}^{-1}\right]$ & value & characteristics \\
\hline$F_{N} \leq-25$ & 0.1 & very low \\
$-25<F_{N} \leq 0$ & 0.3 & low \\
$0<F_{N} \leq 25$ & 0.5 & high \\
$25<F_{N} \leq 50$ & 0.7 & very high \\
$F_{N}>50$ & 0.9 & extremely high \\
\hline
\end{tabular}


deposition was disregarded, similar to certain processes resulting in nitrogen losses, such as volatilization (Søgaard et al. 2002; Huijsmans et al. 2003), surface runoff and soil erosion. It was assumed that the predicted emission of nitrates into groundwater depends on the relationship between the predicted amount of nitrogen fertilization and the ability of crops to utilize this nitrogen fertilization $\left(F_{N}\right)$. The predicted $F_{N}$ relationship was calculated as the difference between the total annual effective nitrogen load $\left(N_{a}\right)$ and the maximum annual nitrogen load that could be utilized by the crop species under the given agronomic conditions $\left(N_{d}\right)$ according to Eq. (8):

$$
F_{N}=N_{a}-N_{d}=N_{a n}+N_{a m}+N_{a s}-N_{d}
$$

where $N_{a n}$ is the effective nitrogen load stemming from natural fertilization, $\mathrm{kg} \cdot \mathrm{ha}^{-1} \cdot \mathrm{y}^{-1}$ (Eq. 9), $N_{a m}$ is the nitrogen load originating from mineral fertilization, $\mathrm{kg} \cdot \mathrm{ha}^{-1} \cdot \mathrm{y}^{-1}$, and $N_{a s}$ is the effective nitrogen load contained in the soil, $\mathrm{kg} \cdot \mathrm{ha}^{-1} \cdot \mathrm{y}^{-1}$ (Eq. 10).

$$
N_{a n}=N_{n} \cdot \beta
$$

where $N_{n}$ is the nitrogen dose originating from manure, $\mathrm{kg} \cdot \mathrm{ha}^{-1} \cdot \mathrm{y}^{-1}$, and $\beta$ is a correction coefficient that determines the effectiveness of nitrogen stemming from manure relative to nitrogen originating from mineral fertilizers (Jensen 2013).

$$
N_{a s}=N_{s} \cdot \alpha
$$

where $N_{s}$ is the stock of mineral nitrogen in soil, $\mathrm{kg} \cdot \mathrm{ha} \mathrm{a}^{-1} \cdot \mathrm{y}^{-1}$, and $\alpha$ is a correction coefficient that determines the effectiveness of soil nitrogen relative to nitrogen stemming from mineral fertilizers (Stanford et al. 1973).

To obtain the total amount $N_{n}$ applied to crops in a given GSPZ, the nitrogen loads produced by the animals reared in the region should be summed depending on the farming system. The total annual amounts of nitrogen originating from both the various fertilizer types and soil nitrogen were divided by the area of fertilized land in the GSPZ to determine the nitrogen load per unit area.

$P A$ classification in fertilized areas based on the difference between the nitrogen fertilization level and potential utilization by crops is presented in Table 4 . If $F_{N}$ is negative, the probability is low or very low $(P A \leq 0.3)$. Consequently, no adverse effect is assumed $(A E=0)$, which indicates no risk to the well field $(R=0)$.

\subsection{Adverse Effect of an Unwanted Event}

The maximum concentration attainable by a chemical emitted by the PSC in the aquifer situated beneath the source $\left(c_{\max }\right)$ is the sum of the predicted injection concentration of the chemical transported through the vadose zone into groundwater $\left(c_{i n j}\right)$ and the concentration originally present in the aquifer due to geogenic and/or anthropogenic causes $\left(c_{0}\right)$. The injection concentration $\left(c_{i n j}\right)$ is the concentration in water percolating through the vadose zone. The maximum concentration $\left(c_{\max }\right)$ attainable by a chemical compound in the aquifer is:

$$
c_{\text {max }}\left(Q_{f}+Q_{i}\right)=c_{0} \cdot Q_{f}+c_{i n j} \cdot Q_{i}
$$

hence: 


$$
c_{\text {max }}=\frac{c_{0} \cdot Q_{f}+c_{i n j} \cdot Q_{i}}{Q_{f}+Q_{i}}
$$

where $Q_{f}$ is the groundwater flux into the aquifer and $Q_{i}$ is the groundwater flux through the vadose zone beneath the PSC.

The adverse effect of an unwanted event $(A E)$ reflects the potential contamination of groundwater flowing into the well field. This effect is determined as the ratio of the predicted concentration attainable by a given chemical released by the PSC in water abstracted from the well $\left(c_{w}\right)$ to its permissible concentration in drinking water $\left(c_{t r}\right)$ :

$$
\begin{gathered}
c_{w} \leq c_{t r} \rightarrow A E=0 \quad \text { (no adverse effect) } \\
c_{w}>c_{t r} \rightarrow A E=1 \quad \text { (adverse effect present) }
\end{gathered}
$$

The permissible concentration limit of a chemical compound in drinking water $\left(c_{t r}\right)$ corresponds to the concentration stipulated in relevant legal acts for water directed to the water supply network after disinfection.

The concentration attainable by a chemical compound emitted by a PSC in water abstracted from the well $\left(c_{w}\right)$ depends on the maximum concentration in groundwater beneath the PSC $\left(c_{\max }\right)$ and the concentration originally present in the aquifer $\left(c_{0}\right)$ :

$$
c_{w}=\frac{c_{\max } \cdot\left(Q_{i}+Q_{f}\right)+c_{0} \cdot\left(Q_{w}-Q_{i}-Q_{f}\right)}{Q_{w}}
$$

where $Q_{w}$ is the well pumping rate.

The predicted maximum concentration reached by the contaminant $\left(c_{\max }\right)$ was determined with an analytical method at the time upon reaching the groundwater table, considering the processes associated with mass migration. Details of the analytical method used to predict mass migration through the vadose zone can be found in the Supplementary Materials - Sect. 1 .

In a given fertilized area, $A E$ was determined if the $P A$ was at least high (Fig. 2, Table 5). To calculate the predicted nitrate injection concentration $\left(\mathrm{mg} \cdot \mathrm{L}^{-1}\right)$ migrated from the topsoil through the unsaturated zone into groundwater $\left(c_{\mathrm{NO}_{3}}\right)$, the following equation was used:

$$
c_{i n j}=c_{\mathrm{NO}_{3}}=\frac{F_{N}}{I_{e}} \cdot 0.443
$$

where $F_{N}$ is the predicted nitrogen load greater than the fertilization needs $\left(\mathrm{kg} \cdot \mathrm{ha}^{-1} \cdot \mathrm{y}^{-1}\right)$ and 0.443 is the conversion factor employed with respect to the units of the parameters occurring in this equation, considering the ratio of the equivalent weights of nitrogen and nitrates.

The nitrate injection concentration $\left(c_{\mathrm{NO} 3}\right)$ is equal to the nitrate concentration in the topsoil leachate due to the assumed absence of denitrification and volatilization during transport through the vadose zone. 


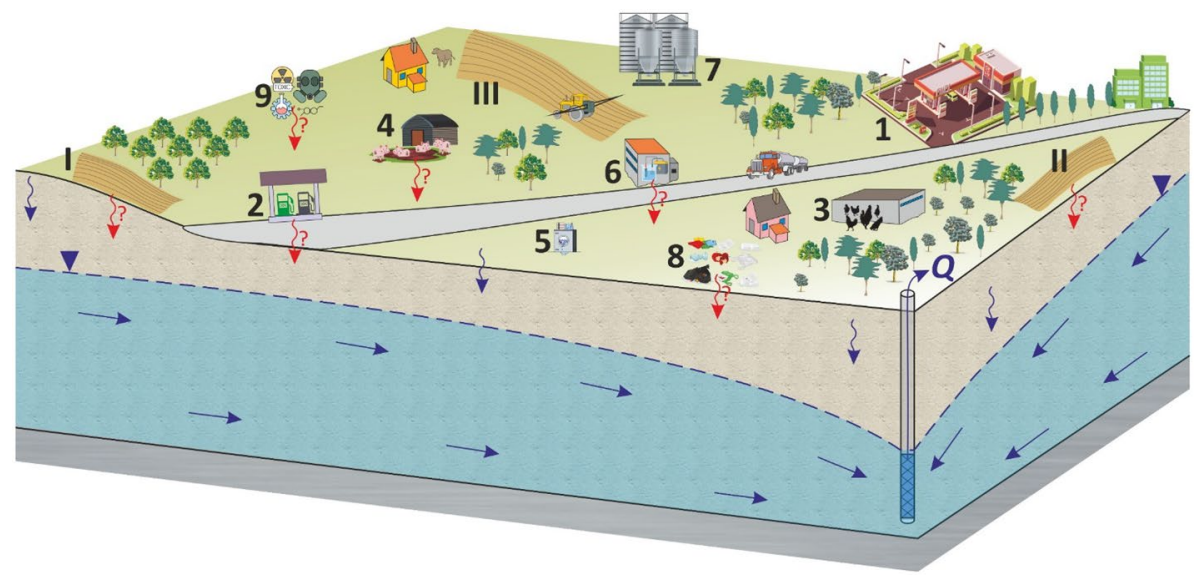

Fig. 3 Schematic 3D cross-section of the example test site (not to scale). The PSCs are numbered in accordance with Tables 7 and S1

\subsection{Annoyance Related to the Adverse Effect}

The annoyance related to the adverse effect to users of abstracted water $\left(A_{A E}\right)$ is determined on the basis of its duration. The duration of annoyance, or supply nonfunctioning $\left(t_{n f}\right)$, is assumed to encompass the number of days during which groundwater drawn from a well would be unfit for drinking and users would have to temporarily rely on another supply source, e.g., water tankers. The annoyance related to the adverse effect increases with the period during which the water supply is interrupted (Table 6).

The contaminant concentration upon reaching the well field $\left(c_{w}\right)$ can be determined analytically, considering the processes associated with mass migration in groundwater, but hydrodynamic dispersion may be disregarded. Details of the analytical method used to predict mass transport in groundwater can be found in the Supplementary Materials - Sect. 2.

Table 6 Classification of the annoyance of an adverse effect to water users

\begin{tabular}{lll}
\hline$t_{n f}$ [days] & $A_{A E}$ & \\
\cline { 2 - 3 } & value & characteristics \\
\hline$t_{n f}=0$ & 0 & none \\
$1 \leq t_{n f} \leq 5$ & 1 & low \\
$5<t_{n f} \leq 10$ & 2 & medium \\
$10<t_{n f} \leq 20$ & 3 & high \\
$t_{n f}>20$ & 4 & very high \\
\hline
\end{tabular}




\section{Materials}

\subsection{Adopted Model}

To illustrate the application of the proposed method, risk analysis of a groundwater well field was conducted considering an idealized model in which frequently occurring selected types of human pressures and typical hydrogeological conditions were assumed (Fig. 3). The phreatic aquifer is unconfined and exhibits a hydraulic conductivity $k=10 \mathrm{~m} \cdot \mathrm{d}^{-1}$, a thickness $m=7 \mathrm{~m}$, and a hydraulic gradient $I=0.1 \%$. In the vadose zone with a thickness $m_{v}=4 \mathrm{~m}$, silty and loamy sand occurs with a volumetric moisture content of $\Theta_{s}=0.2$ (based on Witczak et al. 2011). Precipitation is $P=0.65 \mathrm{~m} \cdot \mathrm{y}^{-1}$. Recharge was estimated via an infiltration method (Staśko et al. 2012) according to Eq. (17):

$$
I_{e}=P \cdot \omega
$$

where $\omega$ is the effective infiltration coefficient of precipitation (for topsoil, $\omega=0.20$, and for compacted municipal waste in a landfill, $\omega=0.30$ ).

Several PSCs are present within the well catchment. These are point sources, i.e., gas stations, industrial plants, landfills, and farms, namely, PSC Nos. 1 to 9, and agricultural areas fertilized with nitrogen where different crops are grown, namely, I, II and III (Table 7, Tables S1 and S2 in the Supplementary Materials - Sect. 3). In the model described, the values of the individual factors determining the probability of an unwanted event stemming from the considered PSCs are not actual values but rather figures adopted to better illustrate the issue of concern.

Table 7 Risk attributed to a given PSC estimated based on the PA qualitative assessment method (refer to Table S1 for the PSC characteristics and assumed values of the factors determining the risk)

\begin{tabular}{|c|c|c|c|c|c|}
\hline PSC & Type & $P A_{i}$ & $\begin{array}{l}P A_{i} \text { quantitative } \\
\text { assessment necessity }\end{array}$ & $A E_{i}$ & $R_{i}$ \\
\hline \multicolumn{6}{|c|}{ Industrial/infrastructure facilities } \\
\hline 1 & gas station & 0.2 & - & 0 & 0 \\
\hline 2 & gas station & 0.6 & + & $\rightarrow$ Tables 9 and S3 & \\
\hline 3 & livestock farm & 0.2 & - & 0 & 0 \\
\hline 4 & livestock farm & 0.8 & + & $\rightarrow$ Tables 9 and S3 & \\
\hline 5 & dry cleaning facility & 0.2 & - & 0 & 0 \\
\hline 6 & electroplating plant & 0.4 & $-{ }^{1)}$ & $\rightarrow$ Tables 10 and $\mathrm{S} 4$ & \\
\hline 7 & juice manufacturing plant & 0.2 & - & 0 & 0 \\
\hline \multicolumn{6}{|c|}{ Landfills } \\
\hline 8 & municipal waste & 0.6 & + & $\rightarrow$ Tables 9 and S3 & \\
\hline 9 & hazardous waste & 0.6 & + & $\rightarrow$ Tables 9 and S3 & \\
\hline \multicolumn{6}{|c|}{ Agricultural crops } \\
\hline I & mixed vegetables & & $\rightarrow$ Table S2 & $\rightarrow$ Tables 10 and S4 & $\rightarrow$ Table 11 \\
\hline II & bean & & & & \\
\hline III & pea & & & & \\
\hline
\end{tabular}

"+": necessary; " - ": not necessary; ${ }^{1)} A E$ assessment required 


\subsection{Sensitivity Analysis}

To analyze the sensitivity of the adopted GSRA method to the variation in the values of the parameters considered, $A E$ assessment was performed under three scenarios (Table 8). Adverse effect analysis concerned those PSCs for which the determined $P A$ indicated that this analysis was necessary. It was assumed that the differences between the analyzed scenarios concerned the set of analyzed PSCs and the amount of water abstracted from the well field. The sensitivity analysis of PSC No. 8 included two suboptions: 8.1 and 8.2 (a larger amount of waste in the landfill under suboption 8.2 over suboption 8.1). It was assumed that the variation in well yield determines the degree of contaminant mass dilution in water pumped from the well and the extent of the well catchment.

\section{Results and Discussion}

Regarding industrial and infrastructure PSCs, the first GSRA stage entails a qualitative assessment of the PA (Table 7). The assessment demonstrated that for PSC No. 6, $P A=0.4$, indicating the need to assess the adverse effects. In terms of those PSCs for which the qualitatively estimated probability $P A>0.5$, it was necessary to proceed to the second stage of probability assessment (additional quantitative assessment). For these PSCs, possible failure initiating accidents and events that condition initiating accidents were assumed, for which, in turn, the estimated occurrence probability values were assumed, i.e., $P a_{i}$ and $P c_{j}$. Possible typical anti-accident protection measures were also assumed together with the estimated probability $\left(P S F_{i}\right)$ of their failure or ineffectiveness (Table 9). In the example described, the values of the individual probabilities are not actual values obtained from source materials but rather figures adopted to better illustrate the issue of concern.

Quantitative assessment of the $P A$ for PSCs Nos. 2, 4, and 9 demonstrated that adequate anti-accident protection measures resulted in the absence of an adverse effect $(A E=0)$ and consequently the absence of risk $(R=0)$. Regarding the municipal landfill (8), given that it was certain that precipitation would infiltrate the landfill $\left(P c_{j}=1.0\right)$ and that it was not insulated, the probability $P A=1$, which necessitated adverse effect $(A E)$ assessment.

In terms of agricultural crops, quantitative $P A$ assessment results are listed in Table S2. For type II and III crops, the calculated excess nitrogen loads $F_{N}$ were high. This occurred due to the lower nitrogen utilization capacities of these vegetables than those of other

Table 8 Scenarios assumed for sensitivity analysis purposes

\begin{tabular}{llll}
\hline Scenario & PSC & Potential adverse impact & $\begin{array}{l}\text { Water abstraction } \\
\left(\mathrm{m}^{3} \cdot \mathrm{d}^{-1}\right)\end{array}$ \\
\hline A & $6,8.1, \mathrm{II}$ & $\begin{array}{l}\text { moderate }- \text { concentration of sulfates in the landfill leachate } \\
c_{s}=1,000 \mathrm{mg} \cdot \mathrm{L}^{-1} ; \text { three PSCs present } \\
\text { significant }- \text { higher sulfate concentration in the landfill } \\
\text { leachate } c_{s}=2,000 \mathrm{mg} \cdot \mathrm{L}^{-1}, \text { higher waste volume, higher } \\
\text { excess nitrogen load stemming from more intensive fertili- } \\
\text { zation of crop III } \\
\text { limited }\end{array}$ & 1,000 \\
C & 8.2, III $\quad$ II & \multicolumn{2}{c}{100} \\
\hline
\end{tabular}


Table 9 Risk due to a given PSC estimated based on PA quantitative assessment (evaluation details in Table S3)

\begin{tabular}{|c|c|c|c|c|c|c|}
\hline PSCs and failure initiating accidents & $P a_{i}$ & $P A_{B Z}$ & $P S F$ & $P A_{i}$ & $A E_{i}$ & $R_{i}$ \\
\hline \multicolumn{7}{|l|}{ 2. Gas station } \\
\hline - damage to a gas pump & 0.01 & 0.0005 & 0.001 & $5 \mathrm{E}-7$ & 0 & 0 \\
\hline - leakage of fuel tank & 0.01 & & & & & \\
\hline \multicolumn{7}{|l|}{ 4. Livestock farm } \\
\hline $\begin{array}{l}\text { leaking insulation of the slurry } \\
\text { and dung storage areas }\end{array}$ & 0.25 & 0.125 & 0.01 & 0.00125 & 0 & 0 \\
\hline \multicolumn{7}{|l|}{ 8. Municipal waste landfill } \\
\hline $\begin{array}{l}\text { - no insulation from the ground, } \\
\text { - no cover }\end{array}$ & 1.0 & 1.0 & & 1.0 & $\begin{array}{l}\rightarrow \text { Tables } 10 \\
\text { and S4 }\end{array}$ & \\
\hline \multicolumn{7}{|l|}{ 9. Hazardous waste landfill } \\
\hline - ground insulation leaking & 0.1 & 0.001 & 0.05 & $5 \mathrm{E}-5$ & 0 & 0 \\
\hline - landfill drainage damage & 0.05 & & & & & \\
\hline
\end{tabular}

typical crops. As a result, for both crops, the quantitatively calculated $P A$ was extremely high $(P A=0.9)$. Hence, it was necessary to assess the $A E$.

Adverse effect assessment was performed under the three scenarios adopted to analyze the sensitivity of the method (Tables 8 and 10).

Scenario A

In regard to PSC No. 6, the calculated vertical migration time of chromium through the vadose zone, considering delay due to sorption, amounts to $t_{v C r}=26.3$ years. This indicates the key role of sorption in $A E$ risk assessment since the calculated chromium concentration in the well 25 years after possible leakage of this PSC remains lower than the permissible value in drinking water. This suggests no adverse effect and no risk to the well originating from this PSC throughout the assumed time horizon (Table 11).

In regard to PSC No. 8.1, the sulfate concentration in well water is lower than the permissible limit for drinking water. This suggests no adverse effects and no risk to the well field. This is attributed to sulfate concentration reduction during transport to the well because of leachate dilution after mixing with clean influent stream water.

Regarding crop No. II, the predicted nitrate concentration in well water does not exceed the permissible limit for drinking water, indicating no adverse effect and consequently no risk to the well field stemming from this PSC. This is attributed to the reduction in contaminant concentration due to the mixing of leachate originating from crop fertilization with the water into the aquifer.

\section{Scenarios B and C}

The results obtained under both scenarios are similar and indicate a threat to the well field originating from the landfill under options 8.1 and 8.2 and from crops II and III (Tables 10 and 11). As the landfill is not insulated from the ground, the adverse effect of its impact under both options is permanent, resulting in the need for wells to be shut in for a long time. This will create a very high annoyance to water users. Hence, $A_{A E i}=4$ was adopted. Therefore, the projected risk to the well field stemming from this PSC is $R_{i}=16$. Similarly, regarding crops, since crops II and III are perennial crops, the adverse effect of excess nitrogen fertilization also persists for many years, requiring long-term well field closure. This situation causes a very high annoyance to water users $\left(A_{A E i}=4\right)$, so $R_{i}=16$. 


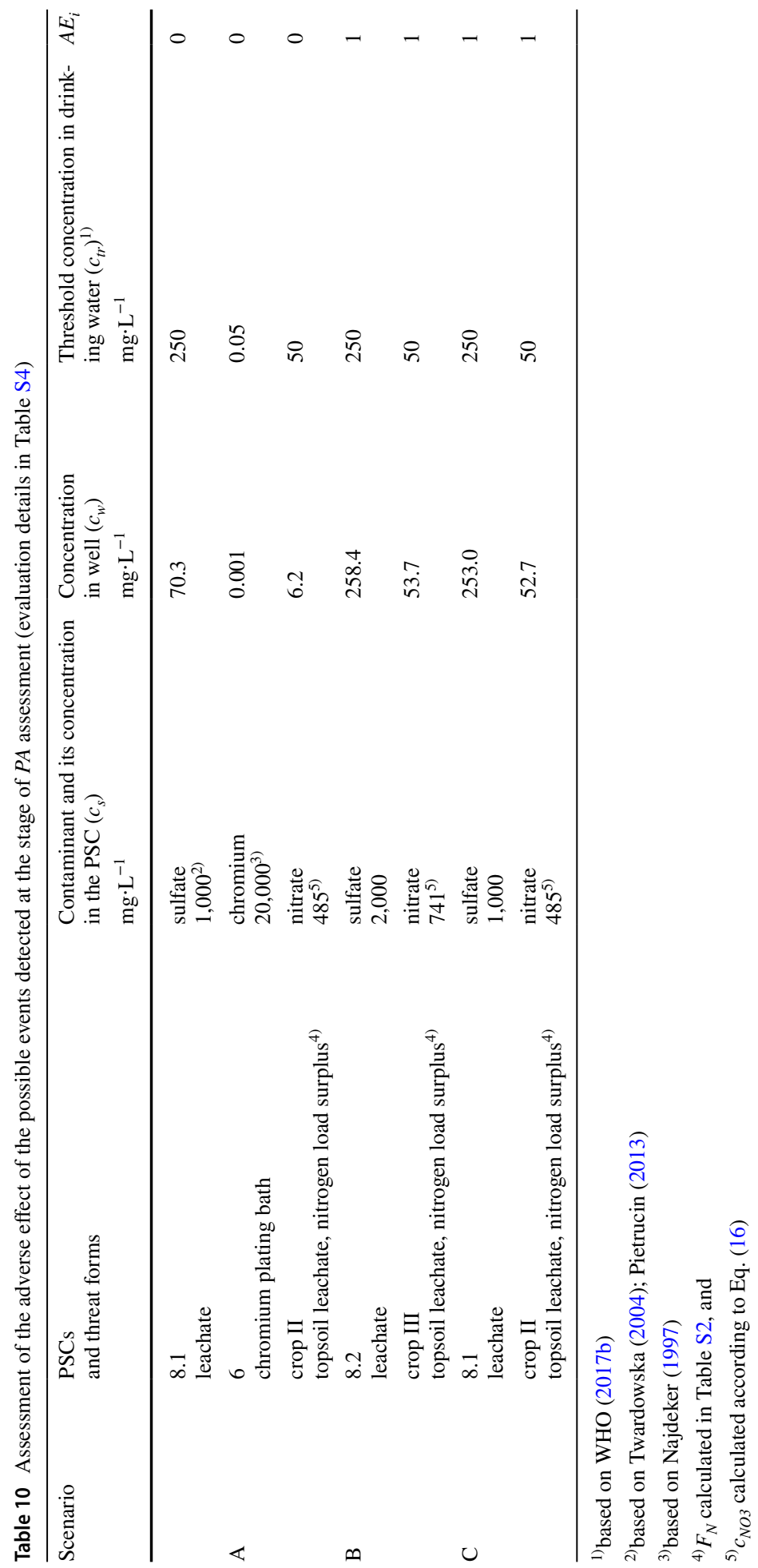


Table 11 Summary of the GSRA results

\begin{tabular}{llllllll}
\hline PSC No & 6 & 8.1 & 8.2 & II & III & $R$ & GSPZ establishment \\
\hline \multicolumn{2}{l}{ Scenario A } \\
$L U_{i}$ & 4 & 4 & - & 4 & - & 0 & not required \\
$A_{A E i}$ & 0 & 0 & - & 0 & - & & \\
$R_{i}$ & 0 & 0 & - & 0 & - & & \\
Scenario B & & & & & & \\
$L U_{i}$ & - & - & 4 & - & 4 & 16 & required \\
$A_{A E i}$ & - & - & 4 & - & 4 & & \\
$R_{i}$ & - & - & 16 & - & 16 & & \\
Scenario C & & & & & & \\
$L U_{i}$ & - & 4 & - & 4 & - & 16 & required \\
$A_{A E i}$ & - & 4 & - & 4 & - & & \\
$R_{i}$ & - & 16 & - & 16 & - & & \\
\hline
\end{tabular}

" - not applicable

Scenario B indicates that despite the unchanged amount of water flowing into the well over Scenario A, there exists an adverse effect of the PSC impact and, therefore, a risk to the well field. This is the effect of human pressure under scenario B, i.e., a higher contaminant concentration occurs in the leachate present under the larger landfill, thus affecting a larger cultivation area, and its adoption in the analysis of crop III, characterized by a lower maximum effective nitrogen load than that of crop II, was considered under scenario A.

In addition to the magnitude of the dissolved contaminant load in the leachate of these PSCs, the ratio of the amount of water pumped through the well to the amount of water flowing below these PSCs into the well plays an important role in assessing the threat to the well field. The difference between these figures is the amount of uncontaminated groundwater inflow. Under scenario A, the considerable amount of water abstracted from the well results in notable contaminant plume dilution due to the water flowing laterally into the well from the entire well catchment. As a result, the averaged contaminant concentration in the inflowing water into the well is lower than that in the inflowing water into a well experiencing less water abstraction. Under scenario $\mathrm{C}$, the inflow of uncontaminated groundwater from outside the PSCs threatening the well field is low. As a result, the proportion of contaminants in the inflowing water into the well is higher, and consequently, the risk increases. Where the amount of abstracted water is small, even a small local PSC can pose a risk to the well field. Nevertheless, proper GSRA should also consider the analysis of hydrogeological conditions and distribution of the hydrodynamic field in terms of the assumed well yield, which greatly affects the extent and shape of the WHPA.

The probability of groundwater contamination as a result of overfertilization in agricultural areas may vary over time, depending on crop species changes. The total nitrogen load originating from the different types of manure obtained from various species of livestock may also vary. The types and amounts of mineral fertilizers may also differ. The probability of exceeding prescribed fertilizer dosage rates may also exhibit spatial variation depending on the crop species grown, soil category and nitrogen load originating from the different sources occurring in individual GSPZ regions. To predict the total nitrogen load as accurately as possible, analyses should be carried out of individual agricultural subareas.

The above considerations indicate that it is important to optimize the amount of water abstracted from the well or distribute the water abstraction amount between individual 
wells in a multiwell field under nitrogen fertilization optimization to protect well fields against a high risk resulting in their closure (Salcedo-Sanchez et al. 2013; Zdechlik and Kałuża 2019). Ghandi and Roozbahani (2020) presented how the risk to the drinking water supply can be managed under critical conditions if it is impossible to avoid these conditions.

Where a contaminant is continuously emitted into groundwater, the annoyance to water users plays a key role in the assessment of the resulting risk. The outcome of risk analysis also depends on the adverse impact of PSCs and the effect of unwanted events. Comparable results of regional groundwater risk analysis were obtained by Huan et al. (2018) and Li et al. (2020), who applied a similar approach accounting for the groundwater intrinsic vulnerability and contaminant potential quantity, representing the hazard originating from land use activities, as two of the three risk factors considered. Generally, similar results were also obtained by Huan et al. (2020) in a risk analysis of groundwater sources due to the presence of livestock farms and landfills. They applied a similar process-based approach, considering mass transport through an unsaturated zone and an aquifer, via numerical simulations. Therefore, it seems feasible and effective to combine their method and tool with our approach.

\section{Conclusions}

Although the proposed method is extensive, the GSRA results obtained as a result of its application should provide a robust basis for policymakers when making decisions on GSPZ establishment.

As the performed GSRA concerns a specific period, another analysis is required after this period. This is attributed to possible changes in land use, technical conditions of the PSCs, agricultural production and related fertilization practices.

The reliable performance of GSRA requires the involvement of a multidisciplinary team and is a difficult task. The analysis complexity depends on the manner of land use assessment and diversity of the PSCs occurring within the projected GSPZ.

It is also necessary to improve the methods for assessment adaptation of the probability of industrial accidents and adverse natural, economic, and legal events to environmental risk analysis. This issue, although very difficult, must be resolved because without considering these probabilities, these assessments will inevitably be burdened by uncertainty.

The proposed process-based holistic GSRA method, which accounts for different types of PSCs, can also be applied, with minor modifications, to regional analysis of the groundwater contamination risk. Assessing the need for groundwater protection on a regional scale is important in light of the progressing depletion of groundwater resources.

Supplementary Information The online version contains supplementary material available at https://doi. org/10.1007/s11269-021-02898-0.

Acknowledgements The authors thank the editor, the associate editor, and anonymous reviewers for their valuable comments that helped us to improve the manuscript.

Author Contributions Robert Duda and Robert Zdechlik designed the study. Robert Zdechlik prepared the data for analysis and conducted the research. Jarosław Kania participated in the research. Robert Duda wrote the first draft of the manuscript, which was edited and enhanced by Robert Zdechlik. All authors contributed to manuscript review. 
Funding This research was supported by the Ministry of Education and Science, Poland, under Grant No. 16.16.140.315.

Data Availability Yes.

\section{Declarations}

Ethical Approval All work complies with ethical standards.

Consent to Participate All authors give their permission.

Consent to Publish All authors give their permission.

Competing Interests The authors declare no competing interests.

Open Access This article is licensed under a Creative Commons Attribution 4.0 International License, which permits use, sharing, adaptation, distribution and reproduction in any medium or format, as long as you give appropriate credit to the original author(s) and the source, provide a link to the Creative Commons licence, and indicate if changes were made. The images or other third party material in this article are included in the article's Creative Commons licence, unless indicated otherwise in a credit line to the material. If material is not included in the article's Creative Commons licence and your intended use is not permitted by statutory regulation or exceeds the permitted use, you will need to obtain permission directly from the copyright holder. To view a copy of this licence, visit http://creativecommons.org/licenses/by/4.0/.

\section{References}

Abedzadeh S, Roozbahani A, Heidari A (2020) Risk assessment of water resources development plans using fuzzy fault tree analysis. Water Resour Manage 34:2549-2569. https://doi.org/10.1007/ s11269-020-02578-5

Duda R, Klebert I, Zdechlik R (2020) Groundwater pollution risk assessment based on vulnerability to pollution and potential impact of land use forms. Pol J Environ Stud 29(1):87-99. https://doi.org/10.15244/pjoes/ 104362

Enzenhoefer R, Binning PJ, Nowak W (2015) STakeholder-Objective Risk Model (STORM): Determining the aggregated risk of multiple contaminant hazards in groundwater well catchments. Adv Water Resour 83:160-175. https://doi.org/10.1016/j.advwatres.2015.05.015

Enzenhoefer R, Nowak W, Helmig R (2012) Probabilistic exposure risk assessment with advective-dispersive well vulnerability criteria. Adv Water Resour 36:121-132. https://doi.org/10.1016/j.advwatres.2011.04. 018

Ghandi M, Roozbahani A (2020) Risk management of drinking water supply in critical conditions using fuzzy PROMETHEE V technique. Water Resour Manage 34:595-615. https://doi.org/10.1007/s11269-019-02460-Z

Huan H, Hu L, Yang Y, Jia Y, Lian X, Ma X, Jiang Y, Xi B (2020) Groundwater nitrate pollution risk assessment of the groundwater source field based on the integrated numerical simulations in the unsaturated zone and saturated aquifer. Environ Int 137:105532. https://doi.org/10.1016/j.envint.2020.105532

Huan H, Wang J, Lai D, Teng Y, Zhai Y (2015) Assessment of well vulnerability for groundwater source protection based on a solute transport model: a case study from Jilin City, northeast China. Hydrogeol J 23(3):581-596. https://doi.org/10.1007/s10040-014-1211-4

Huan H, Zhang BT, Kong H, Li M, Wang W, Xi B, Wang G (2018) Comprehensive assessment of groundwater pollution risk based on HVF model: A case study in Jilin City of northeast China. Sci Total Environ 628-629:1518-1530. https://doi.org/10.1016/j.scitotenv.2018.02.130

Huijsmans JFM, Hol JMG, Vermeulen GD (2003) Effect of application method, manure characteristics, weather and field conditions on ammonia volatilization from manure applied to arable land. Atmos Environ 37:3669-3680. https://doi.org/10.1016/S1352-2310(03)00450-3

Jensen LS (2013) Animal manure fertiliser value, crop utilisation and soil quality impacts. In: Animal Manure Recycling: Treatment and Management. Sommer SG, Christensen ML, Schmidt T, Jensen LS (eds), John Wiley \& Sons. https://doi.org/10.1002/9781118676677.ch15

Li F, Zhao Y, Feng P, Zhang W, Qiao J (2015) Risk assessment of groundwater and its application. Part I: risk grading based on the functional zoning of groundwater. Water Resour Manag 29(8):2697-2714. https:// doi.org/10.1007/s11269-015-0964-4 
Li F, Zhu J, Deng X, Zhao Y, Li S (2018) Assessment and uncertainty analysis of groundwater risk. Environ Res 160:140-151. https://doi.org/10.1016/j.envres.2017.09.030

Li X, Wu H, Qian H (2020) Groundwater contamination risk assessment using intrinsic vulnerability, pollution loading and groundwater value: a case study in Yinchuan plain, China. Environ Sci Pollut R 27:4559145604. https://doi.org/10.1007/s11356-020-10221-4

Lima ML, Romanelli A, Calderon G, Massone H (2019) Multi-criteria decision model for assessing groundwater pollution risk in the urban-rural interface of Mar del Plata City (Argentina). Environ Monit Assess 191(6):347. https://doi.org/10.1007/s10661-019-7485-1

Locatelli L, Binning PJ, Sanchez-Vila X, Lemming Søndergaard G, Rosenberg L, Bjerg PL (2018) A simple contaminant fate and transport modelling tool for management and risk assessment of groundwater pollution from contaminated sites. J Contam Hydrol 221:35-49. https://doi.org/10.1016/j.jconhyd.2018.11.002

Modarres M, Kim IS (2020) Probabilistic risk assessment. In: Reference module in Earth systems and environmental sciences, Elsevier. https://doi.org/10.1016/B978-0-12-409548-9.12161-X

Najdeker E (1997) Trivalent chromium plating baths, 1. Literature overview and primary investigations. Materialy Elektroniczne, 25(2):26-34 (in Polish)

Ostrom L, Wilhelmsen C (2019) Probabilistic risk assessment. In: Risk assessment - tools, techniques, and their applications. 251-260, John Wiley \& Sons. https://doi.org/10.1002/9781119483342.ch18

Pietrucin D (2013) Monitoring of the aquatic environment of an industrial area with multiple sources of pollution. Bull Geograph Phys Geograph Series 6:43-58. https://doi.org/10.2478/bgeo-2013-0003

Rodak C, Silliman S (2012) Probabilistic risk analysis and fault trees: Initial discussion of application to identification of risk at a wellhead. Adv Water Resour 36:133-145. https://doi.org/10.1016/j.advwatres.2011. 02.005

Salcedo-Sanchez ER, Esteller MV, Garrido Hoyos SE, Martinez-Morales M (2013) Groundwater optimization model for sustainable management of the Valley of Puebla aquifer, Mexico. Environ Earth Sci 70:337351. https://doi.org/10.1007/s12665-012-2131-z

Søgaard HTS, Sommer SG, Hutchings NJ, Huijsmans JFM, Bussink DW, Nicholson F (2002) Ammonia volatilization from field-applied animal slurry - the ALFAM model. Atmos Environ 36:3309-3319. https:// doi.org/10.1016/S1352-2310(02)00300-X

Stanford G, Legg JO, Smith SJ (1973) Soil nitrogen availability evaluations based on nitrogen mineralization potentials of soils and uptake of labeled and unlabeled nitrogen by plants. Plant Soil 39:113-124. https:// doi.org/10.1007/BF00018050

Staśko S, Tarka R, Olichwer T (2012) Groundwater recharge evaluation based on the infiltration method. In: Maloszewski P, Witczak S, Malina G (eds), Groundwater Quality Sustainability. Intern Assoc Hydrogeol Selected Papers 17:189-197

Su X, Wang H, Zhang Y (2013) Health risk assessment of nitrate contamination in groundwater: a case study of an agricultural area in northeast China. Water Resour Manag 27:3025-3034. https://doi.org/10.1007/ s11269-013-0330-3

Teng YG, Zuo R, Xiong Y, Wu J, Zhai YZ, Su J (2019) Risk assessment framework for nitrate contamination in groundwater for regional management. Sci Total Environ 697:134102. https://doi.org/10.1016/j.scitotenv. 2019.134102

Troldborg M, Binning PJ, Nielsen S, Kjeldsen P, Christensen AG (2009) Unsaturated zone leaching models for assessing risk to groundwater of contaminated sites. J Contam Hydrol 105:28-37. https://doi.org/10. 1016/j.jconhyd.2008.11.002

Twardowska I (2004) Assessment of pollution potential from solid waste. In: Twardowska I, Allen HE, Kettrup AF, Lacy WJ (eds) Solid waste: assessment, monitoring and remediation. Waste Manag Series, 4, Elsevier, Amsterdam

WHO (2017a) Global status report on water safety plans: A review of proactive risk assessment and risk management practices to ensure the safety of drinking-water. World Health Organization, Geneva. https://apps. who.int/iris/handle/10665/255649

WHO (2017b) Guidelines for drinking-water quality: Fourth edition incorporating the first Addendum. World Health Organization, Geneva. https://www.who.int/publications/i/item/9789241549950

Witczak S, Duda R, Żurek A, Górski J, Dragon K et al (2011) Groundwater vulnerability map of Poland, 1:500 000. Ministry of Environment, Publ. by AGH University of Science and Technology, Krakow, (in Polish with English translation)

Zambito Marsala R, Capri E, Russo E, Barazzoni L, Peroncini E et al (2020) Influence of nitrogen-based fertilization on nitrates occurrence in groundwater of hilly vineyards. Sci Total Environ 144512https://doi.org/ 10.1016/j.scitotenv.2020.144512

Zdechlik R, Kałuża A (2019) The FEM model of groundwater circulation in the vicinity of the Świniarsko intake, near Nowy Sącz (Poland). Geologos 25:255-262. https://doi.org/10.2478/logos-2019-0028 
Zhang B, Li G, Cheng P, Yeh T-CJ, Hong M (2016) Landfill risk assessment on groundwater based on vulnerability and pollution index. Water Resour Manag 30:1465-1480. https://doi.org/10.1007/ s11269-016-1233-x

Publisher's Note Springer Nature remains neutral with regard to jurisdictional claims in published maps and institutional affiliations. 